Research Article

\title{
Experimental Study on Thermal Expansion Behavior of Concrete under Three-Dimensional Stress
}

\author{
Zhipeng Yu, ${ }^{1,2}$ Fan Zhang $\mathbb{D D}^{1}{ }^{1}$ Xiao $\mathrm{Ma},{ }^{2,3}$ Fujian Yang, ${ }^{2,3}$ Dawei Hu $\mathbb{D}^{2,3}$ and Hui Zhou ${ }^{2,3}$ \\ ${ }^{1}$ School of Civil Engineering, Architecture and Environment, Hubei University of Technology, Wuhan, Hubei 430064, China \\ ${ }^{2}$ State Key Laboratory of Geomechanics and Geotechnical Engineering, Institute of Rock and Soil Mechanics, \\ Chinese Academy of Sciences, Wuhan 430071, China \\ ${ }^{3}$ University of Chinese Academy of Sciences, Beijing 100049, China
}

Correspondence should be addressed to Fan Zhang; fanzhang@aliyun.com

Received 26 January 2021; Revised 1 March 2021; Accepted 1 March 2021; Published 9 March 2021

Academic Editor: Chi Yao

Copyright (C) 2021 Zhipeng Yu et al. This is an open access article distributed under the Creative Commons Attribution License, which permits unrestricted use, distribution, and reproduction in any medium, provided the original work is properly cited.

\begin{abstract}
Concrete is widely used in underground engineering and bears three-dimensional stress transmitted by overlying load. When a fire occurs, the thermal expansion of concrete structure under such stress state is different from that under stress-free state. For this purpose, a self-developed real-time high-temperature true triaxial test system was applied to investigate the thermal expansion behavior of concrete under three-dimensional stress state. The thermal expansion strain of concrete under the three-dimensional stress undergoes strain increasing and strain stabilizing stages. At $600^{\circ} \mathrm{C}$, the maximum thermal expansion strain of concrete under the three-dimensional stress is $0.75 \%$. The average coefficient of thermal expansion of concrete under three-dimensional stress condition was then calculated, and its value reaches the minimum of $8.68 \times 10^{-6} /{ }^{\circ} \mathrm{C}$ at $200^{\circ} \mathrm{C}$ and the maximum of $13.41 \times 10^{-6} /{ }^{\circ} \mathrm{C}$ at $500^{\circ} \mathrm{C}$. Comparing the coefficient of thermal expansion of concrete under stress-free condition given by Eurocode, it is found that the three-dimensional stress has an obvious restraint on the thermal expansion of concrete. The research results can provide theoretical basis for the stability analysis of underground engineering concrete structures under hightemperature environment.
\end{abstract}

\section{Introduction}

Underwater and underground tunnels are widely employed in transportation due to their advantages of efficiency, punctuality, safety, and energy conservation. Concrete structure of these tunnels needs to bear three-dimensional stress transmitted by the overlying water, soil, or rock pressure and also occasional heating impact caused by fire accident. Under such condition of three-dimensional stress and high temperature, the concrete structure may generate additional deformation and stress due to thermal expansion, which will affect the safety and stability of the tunnel and threaten the normal operation of the equipment and the lives of personnel [1]. Different form thermal expansion behavior under stress-free condition, the thermal expansion behavior of concrete under three-dimensional stress condition is still not completely understood and is thus of great importance to study.
A large number of experimental studies [2-5] and numerical simulations $[6,7]$ have been performed on the coefficient of thermal expansion (CTE) of concrete materials. Loser et al. [8] proposed a method to measure the CTE of hardened cement-based materials and studied the effect of age on the CTE. Yeon et al. [9] performed in situ CTE test on concrete and found that the CTE of concrete increased slightly after a sudden decrease in a period of time and then tended to stabilize, and the value of CTE of the initial stage was about twice that of the stable phase. Childs et al. [10] developed a method for measuring the CTE of ultra-highstrength cement-based materials using optical fiber sensors. Siddiqui et al. [11] studied the CTE of concrete with different types of aggregates and cement paste volumes and proposed a method to optimize the CTE of concrete. Abdulkareem et al. [12] studied the thermal expansion behavior of geopolymer slurry at high temperature under different heating rates. Turcry et al. [13] studied the effect of temperature on 
the autogenous shrinkage of cement slurry. Zhou et al. [14] established a model based on thermodynamic analysis to predict the CTE of concrete and found that the type of aggregate was the main influencing factor.

The studies mentioned above mainly consider the influences of concrete composition materials, age, water content, and heating rate on thermal expansion behavior. Thermal deformability of concrete is also conditioned by the curing conditions [15] and some of its properties [16]. However, the concrete structure of underwater and underground tunnels is often under three-dimensional stress condition, which is different from the stress-free condition. Joaquín et al. [17] argued that the applied volumetric compressive stress could significantly decrease the volumetric expansion rate of concrete caused by alkali silicate reaction (ASR). Moreover, stress seems to have a great influence on the thermal expansion behavior of other materials, for example, graphite, ceramic, and glass [18-21]. Therefore, it is highly important to investigate the thermal expansion behavior of concrete under three-dimensional stress condition.

In this study, a real-time high-temperature true triaxial test system is especially designed to perform thermal expansion tests on cubic concrete samples under triaxial stress condition, the thermal expansion strain is measured during the heating process, and the CTE under three-dimensional stress condition is analyzed and compared with that under stress-free condition.

\section{Test Preparations}

2.1. Test Equipment. The real-time high-temperature true triaxial test system (see Figure 1) is especially designed to investigate the thermal expansion behavior of geomaterial under triaxial compression stress. The system is mainly composed of three modules: true triaxial loading module, high-temperature control module, and servo control and data acquisition module [22]. The maximum and minimum principal stresses are, respectively, up to 1000 and $200 \mathrm{MPa}$ at a real-time maximum temperature of $600^{\circ} \mathrm{C}$. Meantime, the changes in displacement and stress in the three directions are continuously monitored by Linear Variable Differential Transformer (LVDT) during the loading and heating process. Four groups of detachable rigid heating components are employed for the achievement of real-time high temperature. Each group of heating components is composed of 1 electric thermocouple and 8 heating rods, which are inserted in the 4 corners of the thermoplastic mold steel. The mold steel is used as heat transfer medium to heat the sample, as shown in Figure 2. Therefore, the system can truly simulate the high-temperature and triaxial compression stress environment for the concrete in underground engineering.

2.2. Sample Preparation. According to the mixture proportions of the concrete (see Table 1), the concrete was poured into a cubic sample of $150 \times 150 \times 150 \mathrm{~mm}$. After being cured for 72 hours, the sample was demolded and was

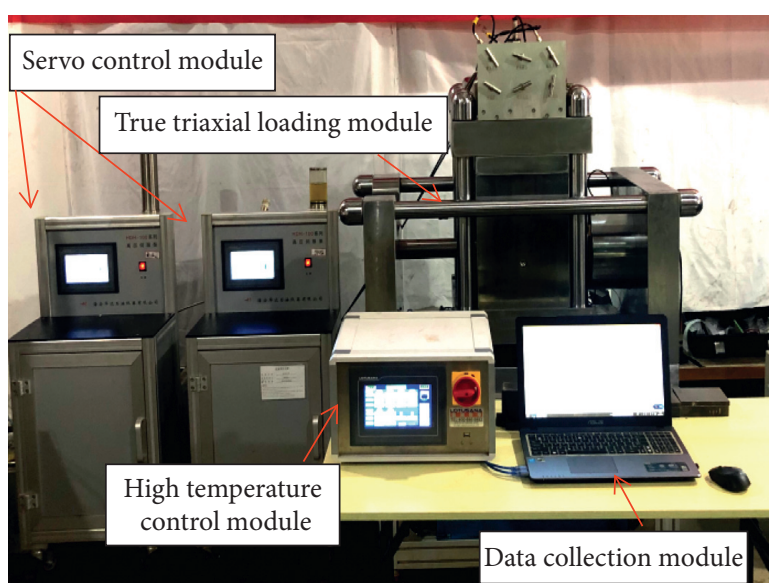

FIgURE 1: Photo of real-time high-temperature true triaxial test system.

placed in a special curing room for 60 days. The special values of the constant temperature and constant humidity for concrete curing are $20 \pm 2^{\circ} \mathrm{C}$ and a relative humidity greater than $95 \%$, respectively. The concrete specimens are put into water and submerged for long term. In order to prevent the concrete from being acidified, add a small amount of lime powder to the water. A quartz sample of $50 \times 50 \times 100 \mathrm{~mm}$ was also prepared to calibrate test results.

In order to reduce the dispersion of test results induced by the heterogeneity of samples, a series of nondestructive detection methods, for example, density test, rebound strength test, and P-wave velocity measurement, were used for screening the samples $[23,24]$. The value ranges of density, rebound strength, and P-wave velocity of the samples after detection methods are $2.423-2.639 \mathrm{~g} / \mathrm{cm}^{3}$, $40.9-46.7 \mathrm{MPa}$, and $4328-4820 \mathrm{~m} / \mathrm{s}$, respectively. It is clear that there is only a small variation range and the prepared samples are thus considered to be relatively homogeneous. This could reduce errors caused by factors such as internal defects of the sample and improve the accuracy of data for subsequent test results.

2.3. Test Condition Setting. Immersed tube tunnel is increasingly used in traffic engineering and thus selected as a case to study. After the analyses of overlying loading on the tunnel $[25,26]$, a hydrostatic pressure of $0.5 \mathrm{MPa}$ is determined and applied on the sample to simulate the threedimensional stress condition.

When a fire occurs in an immersed tube tunnel, the temperature of inflammation point may rise to $1200^{\circ} \mathrm{C}$. The concrete structure cannot withstand such high temperature, and the serious part is easy to collapse. However, considering that the strength loss of concrete is about $60-75 \%$ when temperature reaches $600^{\circ} \mathrm{C}[27,28]$, a dual fire protection of "fire board + aluminum silicate fiber fire blanket" is thus often used in immersed tube tunnels and has the effect of fire prevention and heat insulation from inflammation point [29]. With the help of such protection, the maximum temperature of concrete structure in immersed tube tunnels is below $600^{\circ} \mathrm{C}$. Therefore, it is considered to carry out the 

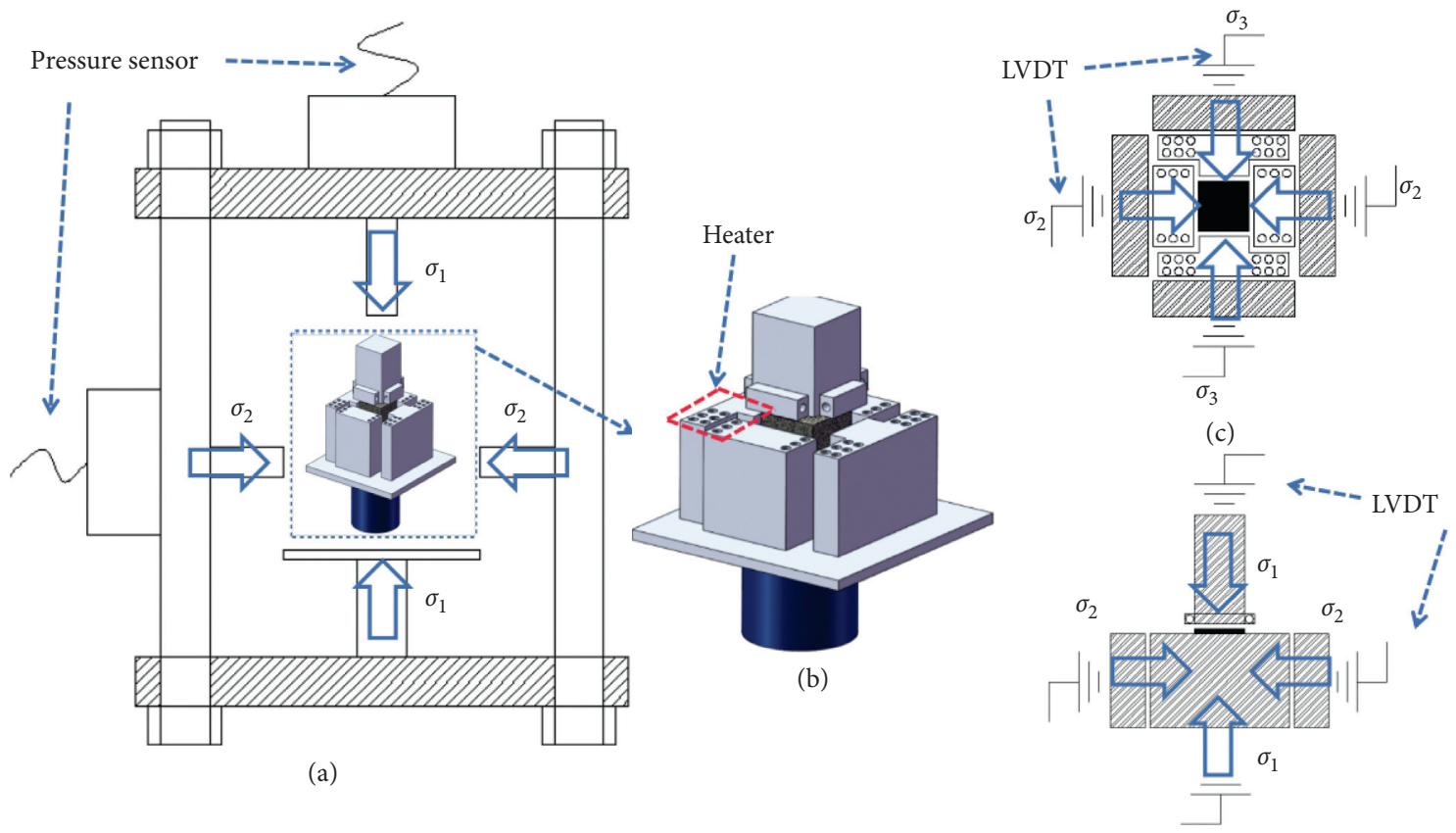

(d)

FIGURE 2: Schematic diagram of real-time high-temperature true triaxial loading system. (a) Real-time high-temperature true triaxial test system. (b) Interior layout drawing of real-time high-temperature true triaxial test system. (c) Schematic of the subsystem for the maximum and intermediate principal stress loading. (d) Schematic of the subsystem for the major principal stress loading.

TABLE 1: Mixture proportions of the concrete used in the experiment.

\begin{tabular}{lccccccc}
\hline $\begin{array}{l}\text { Strength } \\
\text { grade }\end{array}$ & $\begin{array}{c}\text { Cementitious } \\
\text { material }\end{array}$ & $\begin{array}{c}\text { Water cement } \\
\text { ratio }\end{array}$ & $\begin{array}{c}\text { Cement } \\
(\%)\end{array}$ & $\begin{array}{c}\text { Fly ash } \\
(\%)\end{array}$ & $\begin{array}{c}\text { Slag powder } \\
(\%)\end{array}$ & $\begin{array}{c}\text { Sand rate } \\
(\%)\end{array}$ & $\begin{array}{c}\text { Water reducing } \\
\text { agent }\end{array}$ \\
\hline $\mathrm{C} 50$ & $420 \mathrm{~kg} / \mathrm{m}^{3}$ & 0.35 & 45 & 25 & 30 & 43 & $1 \mathrm{~kg} / \mathrm{m}^{3}$ \\
\hline
\end{tabular}

experiment in the range of $600^{\circ} \mathrm{C}$, and 6 temperature levels of $100,200,300,400,500$, and $600^{\circ} \mathrm{C}$ are selected for heating treatment.

2.4. Experiment Procedure. The displacement control is adopted for three-dimensional stress loading, and the loading rate is $0.001 \mathrm{~mm} / \mathrm{s}$. A hydrostatic stress of $0.5 \mathrm{MPa}$ is applied on the samples to simulate the three-dimensional loading and held constant during the following thermal expansion deformation test.

After the load reaches the preset stress, the system is started to heat the sample from room temperature (RT) to the preset temperature T. The system should be kept for $2 \mathrm{~h}$ to ensure uniform heating inside the sample. The heating rate and the temperature relationship between heater and sample surface are shown in Figure 3.

During the heating process, a constant hydrostatic stress of $0.5 \mathrm{MPa}$ is applied on the samples. Three sets of LVDT are arranged in each direction, and each set contains 2 transducers. The arrangement of transducers is shown in Figure 2. The system collects the displacement changes of the concrete in the three directions from the beginning of the temperature rising to the end of the constant temperature. In order to eliminate the error of the instrument itself during the heating process, a quartz sample is first used to calibrate the results. Because the CTE of the quartz sample is about $5.5 \times 10^{-7} /{ }^{\circ} \mathrm{C}$, which is far lower than the CTE of concrete, and the thermal expansion of the quartz sample in the three directions can be ignored, the strains in the three directions in the cases of the quartz sample can be directly used as the thermal expansion strains of the instrument itself.

By eliminating the deformation of the instrument itself, the thermal expansion deformations of concrete under the three-dimensional stress condition can be obtained, and then the three-dimensional thermal expansion strains of the samples under three-dimensional stress condition are calculated.

Considering that the studied concrete is homogeneous and is subjected to a hydrostatic stress, an average value of the thermal expansion strains in the three directions is used to calculate the CTE of the samples under the three-dimensional stress condition. The formulas are written as

$$
\begin{aligned}
\varepsilon_{n}(T) & =\frac{L_{n, T}-L_{n, S}}{L_{n, 0}}, \quad(n=1,2,3), \\
\alpha_{C}(T) & =\frac{1 / n \sum \varepsilon_{n}(T)}{\Delta T},
\end{aligned}
$$

where $\varepsilon_{n}(T)$ and $L_{n, T}$ are the thermal strain and thermal deformation of the concrete in the $n$ direction at a 


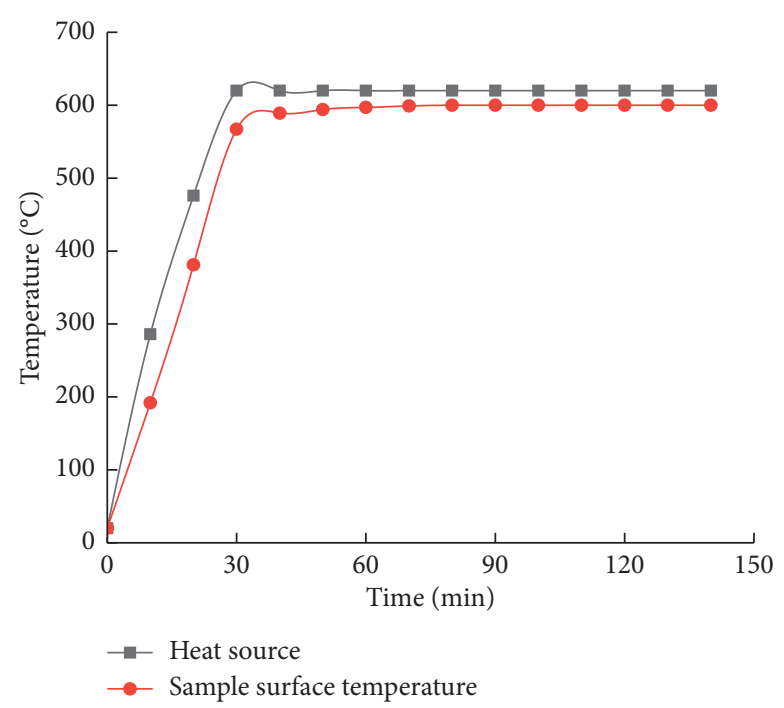

FIgURE 3: The temperature relationship between heater and sample surface.

temperature of $T ; L_{n, 0}$ is the initial length of concrete in the $n$ direction; $L_{n, \mathrm{~S}}$ is the thermal deformation of the quartz in the $n$ direction at a temperature of $T ; \alpha_{\mathrm{C}}(T)$ is thus the average value the CTE under three-dimensional stress; $\Delta \mathrm{T}$ $\left({ }^{\circ} \mathrm{C}\right)$ is the temperature change of the samples.

\section{Test Results of Thermal Expansion Deformations}

3.1. Evolutions of Thermal Expansion Strain during Heating Process. Figures 4(a)-4(f) present the curves of the threedimensional thermal expansion strains versus time under three-dimensional stress condition. In this study, the tensile strains produced by the thermal expansion of concrete are taken as positive. After heating to about $60 \mathrm{~min}$, the thermal expansion strains enter the stable stage. At this time, the three-dimensional thermal expansion strains under threedimensional stress condition basically reach the maximum. At $600^{\circ} \mathrm{C}$, the maximum thermal expansion strain of the concrete under three-dimensional stress reaches $0.75 \%$. The three-dimensional thermal expansion strains of the concrete under three-dimensional stress at various temperatures are summarized in Table 2.

3.2. Average CTE of Concrete under Three-Dimensional Stress Condition. The average CTE of concrete under three-dimensional stress condition is calculated according to Table 2 and equations (1)-(2), and the results are shown in Figure 5. The average CTE of concrete under three-dimensional stress condition presents an S-shaped trend with temperature changes. The CTE of concrete under three-dimensional stress condition presents a downward trend within $100-200^{\circ} \mathrm{C}$, then an upward trend up to $500^{\circ} \mathrm{C}$, and finally a downward trend within $500-600^{\circ} \mathrm{C}$. The CTE of concrete under three-dimensional stress condition reaches its minimum of $8.68 \times 10^{-6} /{ }^{\circ} \mathrm{C}$ at $200^{\circ} \mathrm{C}$ and reaches the maximum of $13.41 \times 10^{-6} /{ }^{\circ} \mathrm{C}$ at $500^{\circ} \mathrm{C}$.

\section{Discussions}

As mentioned above, the thermal expansion property of concrete is highly important for the structure stability analyses of underground and underwater tunnel subjected to fire accident. Previous study indicated that the thermal deformation of cement-based materials is closely related to temperature and stress state [30]. However, the CTE in most of existent standard of cement structures is usually measured under stress-free condition, and the calculation results of thermal deformation of concrete structures based on the CTE under stress-free condition may not be applicable in underground or underwater tunnels. Concrete structures are all subjected to three-dimensional stress. The thermal deformation of the structure is related not only to the temperature load but also to the stress. Using the CTE of concrete under the free-stress state to calculate the thermal expansion of the structure will be excessively exaggerated or small, and the calculation of the structural thermal stress is not accurate. In order to understand the difference between the thermal deformation of concrete under the three-dimensional stress condition and the stress-free condition, a typical CTE model of concrete under stress-free condition, which was suggested by the European Standards [31], is used to compare with the CTE measured in the present work.

To deal with the design of concrete structures for the accidental situation of fire exposure, a formula is suggested by the European Standards to calculate the thermal expansion strain of ordinary concrete and written as follows:

$\Delta l / l=2.3 \times 10^{-11} \mathrm{~T}^{3}+9 \times 10^{-6} \mathrm{~T}-1.8 \times 10^{-4}\left(20^{\circ} \mathrm{C} \leq \mathrm{T} \leq 600^{\circ} \mathrm{C}\right)$.

The comparisons of the CTE of the concrete from the European Standards and the present work are shown in Figure 6. At $100^{\circ} \mathrm{C}$, the CTE of concrete under three-dimensional stress is slightly larger than that given by the European Standards. After $200^{\circ} \mathrm{C}$, the CTE of concrete under stress-free condition is about 1.07-1.47 times of the CTE 


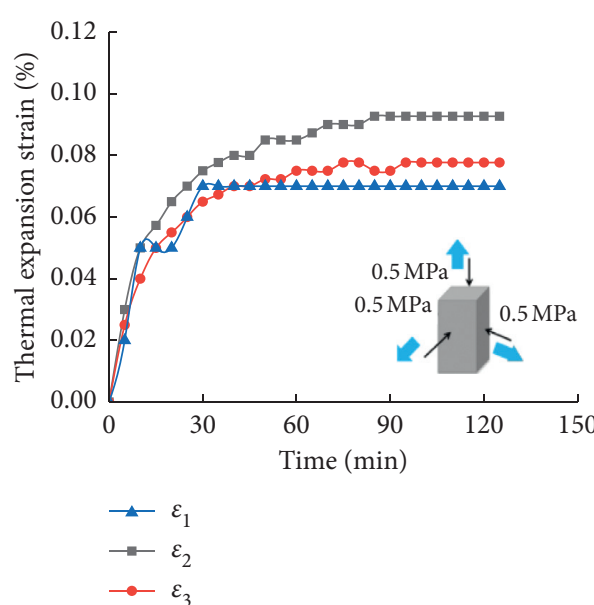

(a)

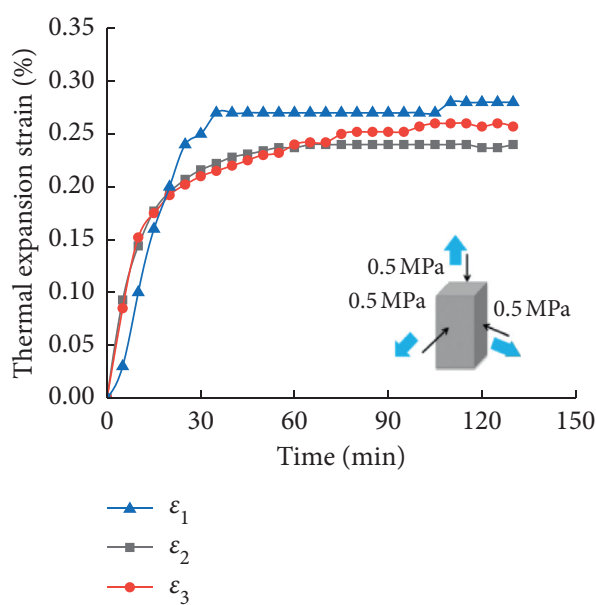

(c)

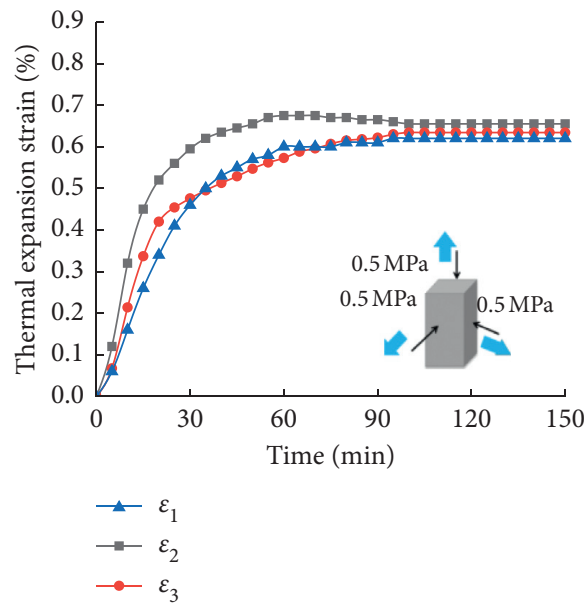

(e)

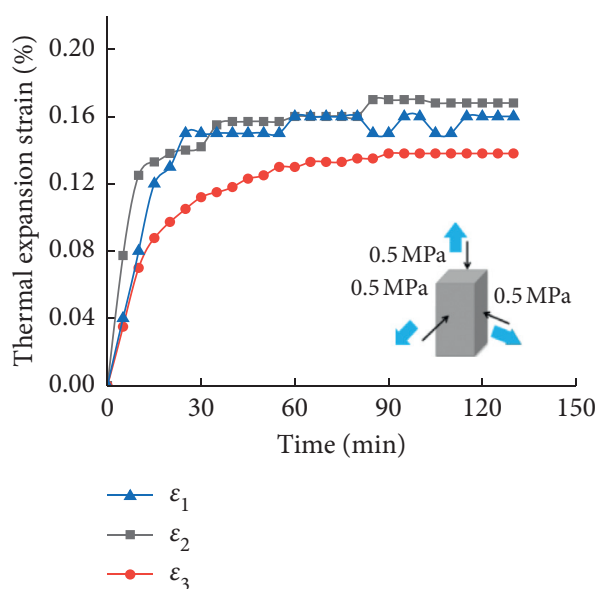

(b)

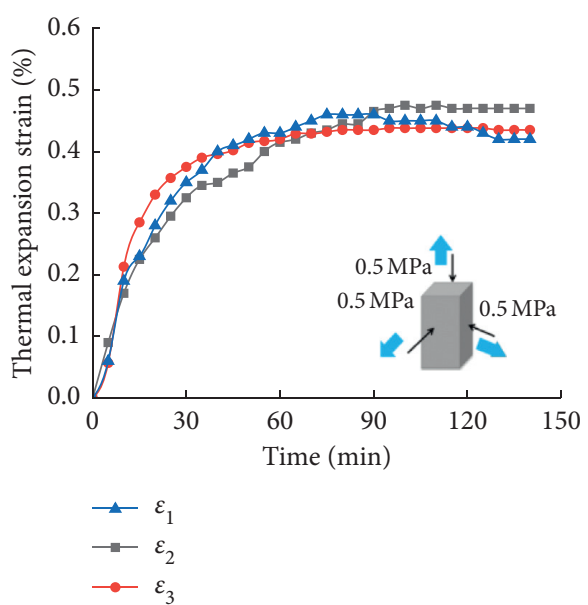

(d)

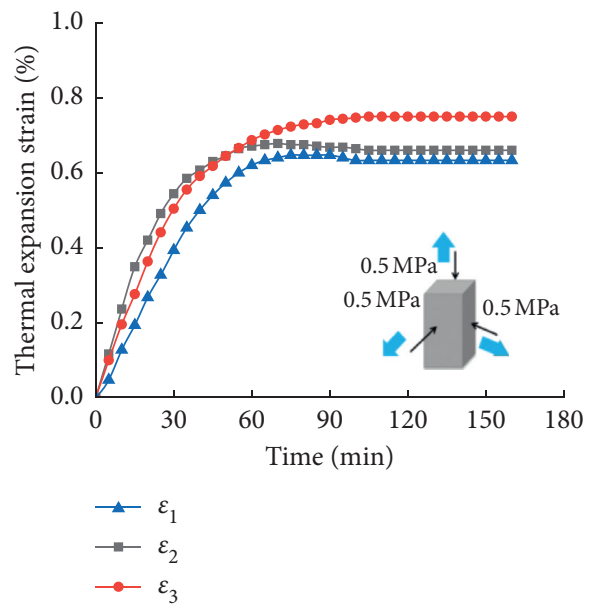

(f)

Figure 4: Thermal expansion strains of concrete under three-dimensional stress condition. (a) $100^{\circ} \mathrm{C}$, (b) $200^{\circ} \mathrm{C}$, (c) $300^{\circ} \mathrm{C}$, (d) $400^{\circ} \mathrm{C}$, (e) $500^{\circ} \mathrm{C}$, and (f) $600^{\circ} \mathrm{C}$.

under three-dimensional stress condition. In other words, the three-dimensional stress condition has obvious restraint effect on the thermal expansion of concrete. The effect of three-dimensional stress on the CTE of concrete could be attributed to two mechanisms, that is, the compression deformation due to degradation of elastic modulus under high temperature [31-35] and restrain of thermal-induced microcracks [36-38]. Therefore, the CTE of concrete under 
TABLE 2: Thermal expansion strains of concrete during heating under three-dimensional stress condition.

\begin{tabular}{lcccccc}
\hline \multirow{2}{*}{ Parameters } & \multicolumn{7}{c}{ Temperature $\left({ }^{\circ} \mathrm{C}\right)$} \\
& 100 & 200 & 300 & 400 & 500 & 600 \\
\hline$\varepsilon_{1}(\%)$ & 0.070 & 0.160 & 0.280 & 0.460 & 0.620 & 0.647 \\
$\varepsilon_{2}(\%)$ & 0.093 & 0.170 & 0.240 & 0.475 & 0.675 & 0.675 \\
$\varepsilon_{3}(\%)$ & 0.078 & 0.138 & 0.260 & 0.438 & 0.634 & 0.750 \\
$\varepsilon_{C}(\%)$ & 0.080 & 0.156 & 0.260 & 0.458 & 0.643 & 0.691 \\
\hline
\end{tabular}

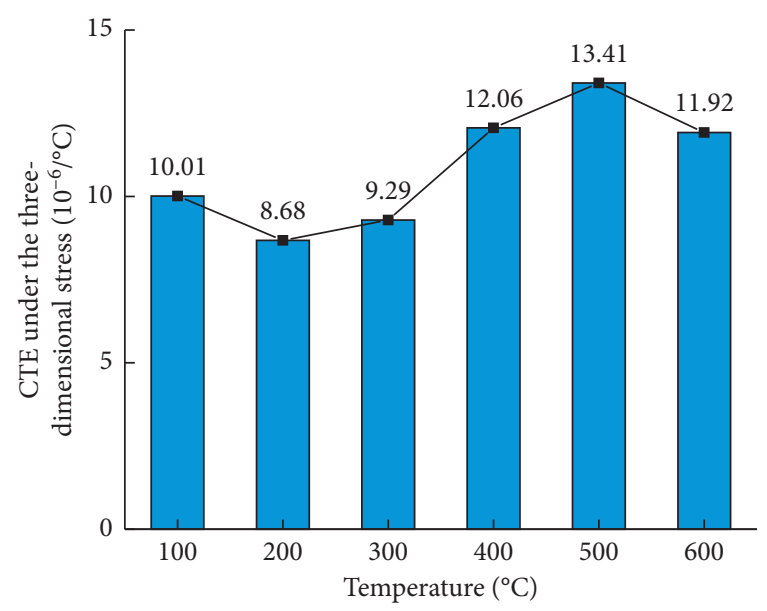

Figure 5: CTE of concrete under three-dimensional stress.

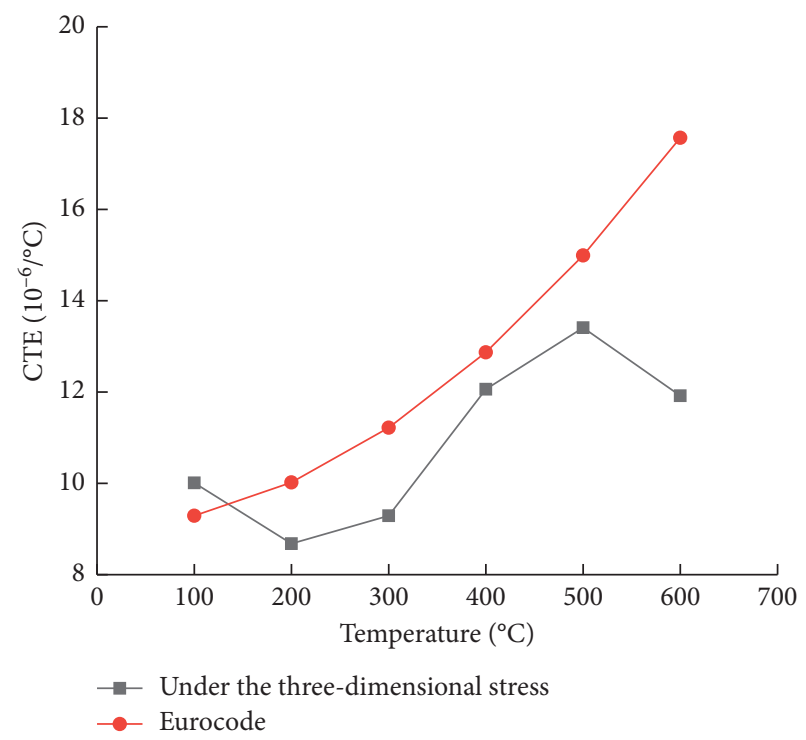

FIgURE 6: Comparisons of the CTE under different conditions.

three-dimensional stress condition is smaller than that under stress-free condition. A similar phenomenon has been also observed on rock materials $[39,40]$.

\section{Conclusions}

Six groups of concrete samples were screened out to perform thermal expansion tests at different temperatures under three-dimensional stress condition. The thermal deformation behavior of the concrete under three-dimensional stress condition was investigated; the CTE was compared with that under stress-free condition. The thermal expansion strain of concrete under the three-dimensional stress undergoes strain increasing and strain stabilizing stages. At $600^{\circ} \mathrm{C}$, the maximum thermal expansion strain of concrete under the three-dimensional stress is $0.75 \%$. The average coefficient of thermal expansion of concrete under three-dimensional stress condition was then calculated, and its value reaches the minimum of $8.68 \times 10^{-6} /{ }^{\circ} \mathrm{C}$ at $200^{\circ} \mathrm{C}$ and the maximum of $13.41 \times 10^{-6} /{ }^{\circ} \mathrm{C}$ at $500^{\circ} \mathrm{C}$. The average CTE of concrete under three-dimensional stress condition presents an S-shaped trend with temperature changes. The CTE of concrete under threedimensional stress condition reaches its minimum of $8.68 \times 10^{-6} /{ }^{\circ} \mathrm{C}$ at $200^{\circ} \mathrm{C}$ and the maximum of $13.41 \times 10^{-6} /{ }^{\circ} \mathrm{C}$ at $500^{\circ} \mathrm{C}$. By comparing the CTE of concrete under stressfree condition suggested by Eurocode, it is found that the three-dimensional stress has a significant restriction on the thermal expansion of concrete. The above research results can provide a theoretical basis for the stability analysis of underground concrete structures under sudden-fire and high-temperature environments.

\section{Data Availability}

The data used to support the findings of this study are available from the corresponding author upon request.

\section{Conflicts of Interest}

The authors declare that they have no conflicts of interest.

\section{Acknowledgments}

The work was supported by the National Key R\&D Program of China (nos. 2018YFC0809600 and 2018YFC0809601), the National Natural Science Foundation of China (nos. 51779252 and 51479193), the China Geological Survey Bureau (no. DD20190128), and the Major Technological Innovation Projects of Hubei (no. 2017AAA128).

\section{References}

[1] G. Wang, D. Barber, P. Johnson, and M. C. Hui, "Fire safety provisions for aged concrete building structures," Procedia Engineering, vol. 62, 2013.

[2] V. Revilla-Cuesta, M. Skaf, J. A. Chica et al., “Thermal deformability of recycled self-compacting concrete under cyclical temperature variations," Materials Letters, vol. 278, 2020.

[3] L. Zuda and R. Černý, "Measurement of linear thermal expansion coefficient of alkali-activated aluminosilicate composites up to $1000^{\circ} \mathrm{C}$," Cement and Concrete Composites, vol. 31, no. 4, pp. 263-267, 2009.

[4] B. Zahabizadeh, A. Edalat-Behbahani, J. Granja et al., "A new test setup for measuring early age coefficient of thermal expansion of concrete," Cement \& Concrete Composites, vol. 98, pp. 14-28, 2002.

[5] S. Ghabezloo, "Effect of porosity on the thermal expansion coefficient: a discussion of the paper "effects of mineral 
admixtures on the thermal expansion properties of hardened cement paste" by Z. H. Shui, R. Zhang, W. Chen, D. Xuan, Constr. Build. Mater. 24 (9) (2010) 1761-1767," Construction and Building Materials, vol. 24, no. 9, pp. 1796-1798, 2010.

[6] C. Zhou, X. Shu, and B. Huang, "Predicting concrete coefficient of thermal expansion with an improved micromechanical model," Construction and Building Materials, vol. 68, pp. 10-16, 2014.

[7] L. M. Mccarthy, J. M. Gudimettla, G. L. Crawford, M. C. Guercio, and D. Allen, "Impacts of variability in coefficient of thermal expansion on predicted concrete pavement performance," Construction and Building Materials, vol. 93, pp. 711-719, 2015.

[8] R. Loser, B. Münch, and P. Lura, "A volumetric technique for measuring the coefficient of thermal expansion of hardening cement paste and mortar," Cement and Concrete Research, vol. 40, no. 7, pp. 1138-1147, 2010.

[9] J. H. Yeon, S. Choi, and M. C. Won, "In situ measurement of coefficient of thermal expansion in hardening concrete and its effect on thermal stress development," Construction and Building Materials, vol. 38, pp. 306-315, 2013.

[10] P. Childs, A. C. L. Wong, N. Gowripalan, and G. D. Peng, "Measurement of the coefficient of thermal expansion of ultra-high strength cementitious composites using fibre optic sensors," Cement and Concrete Research, vol. 37, no. 5, pp. 789-795, 2007.

[11] M. S. Siddiqui and D. W. Fowler, "A systematic optimization technique for the coefficient of thermal expansion of Portland cement concrete," Construction and Building Materials, vol. 88, pp. 204-211, 2015.

[12] O. A. Abdulkareem, A. M. M. A. Bakri, H. Kamarudin et al., "Effects of elevated temperatures on the thermal behavior and mechanical performance of fly ash geopolymer paste, mortar and lightweight concrete," Construction \& Building Materials, vol. 50, pp. 377-387, 2013.

[13] P. Turcry, A. Loukili, L. Barcelo, and J. M. Casabonne, "Can the maturity concept be used to separate the autogenous shrinkage and thermal deformation of a cement paste at early age?" Cement and Concrete Research, vol. 32, no. 9, pp. 1443-1450, 2002.

[14] C. Zhou, B. Huang, and X. Shu, "Micromechanical model for predicting coefficient of thermal expansion of concrete," Journal of Materials in Civil Engineering, vol. 25, no. 9, pp. 1171-1180, 2013.

[15] H. Y. Aruntas, S. Cemalgil, O. Simsek et al., "Effects of super plasticizer and curing conditions on properties of concrete with and without fiber," Materials Letters, vol. 62, pp. 34413443, 2008.

[16] Y. Sun, P. Gao, F. Geng, H. Li, L. Zhang, and H. Liu, "Thermal conductivity and mechanical properties of porous concrete materials," Materials Letters, vol. 209, pp. 349-352, 2017.

[17] J. Liaudat, I. Carol, C. M. López, and V. E. Saouma, "ASR expansions in concrete under triaxial confinement," Cement and Concrete Composites, vol. 86, pp. 160-170, 2018.

[18] L. Doojin and S. Soek, "Modeling the effects of elastic modulus and thermal expansion coefficient on the shrinkage of glass fiber reinforced composites," Composites, Part B Engineering, vol. 146, pp. 98-105, 2018.

[19] N. Khalili, A. Uchaipichat, and A. A. Javadi, "Skeletal thermal expansion coefficient and thermo-hydro-mechanical constitutive relations for saturated homogeneous porous media," Mechanics of Materials, vol. 42, no. 6, pp. 593-598, 2010.
[20] Y. Hirata, "Theoretical analyses of thermal shock and thermal expansion coefficients of metals and ceramics," Ceramics International, vol. 41, no. 1, pp. 1145-1153, 2014.

[21] H. Wang, X. Zhou, L. Sun, J. Dong, and S. Yu, “The effect of stress levels on the coefficient of thermal expansion of a finegrained isotropic nuclear graphite," Nuclear Engineering and Design, vol. 239, no. 3, pp. 484-489, 2009.

[22] X. Ma, G. Wang, D. Hu et al., "Mechanical properties of granite under real-time high temperature and three dimensional stress," International Journal of Rock Mechanics and Mining Sciences, vol. 136, 2020.

[23] T. Y. Guo and L. N. Y. Wong, "Microcracking behavior of three granites under mode I loading: insights from acoustic emission," Engineering Geology, vol. 278, 2020.

[24] M. Alwash, D. Breysse, Z. M. Sbartaï, K. Szilágyi, and A. Borosnyói, "Factors affecting the reliability of assessing the concrete strength by rebound hammer and cores," Construction and Building Materials, vol. 140, pp. 354-363, 2017.

[25] M. Wu, Q. Zhang, and S. Wu, "Risk assessment of operation period structural stability for long and large immersed tube tunnel," Procedia Engineering, vol. 166, pp. 266-278, 2016.

[26] Z. Zhang, W. Lin, H. Ji et al., "Layout and design techniques of cross section for the large immersed tunnel," Procedia Engineering, vol. 166, pp. 37-44, 2016.

[27] A. P. Mouritz and Z. Mathys, "Post-fire mechanical properties of glass-reinforced polyester composites," Composites Science and Technology, vol. 61, no. 4, pp. 475-490, 2001.

[28] F. H. Amundsen, "Studies of driver behavior in Norwegian road tunnels," Tunneling and Underground Space Technology, vol. 9, no. 1, pp. 9-17, 1994.

[29] J. Yao, H. Zhu, and Z. Yan, "Reviews and analysis on fireproof measures used for tunnel structure," Chinese Journal of Underground Space and Engineering, vol. 3, no. 4, pp. 732-736+741, 2007.

[30] H. Zhou, D. Hu, F. Zhang, and J. Shao, "A thermo-plastic/ viscoplastic damage model for geomaterials," Acta Mechanica Solida Sinica, vol. 24, no. 3, pp. 195-208, 2011.

[31] BSEN 1992-1-2, Eurocode 2, Design of Concrete Structures. Part 1.2.General Rules, Structural Fire Design, British Standards Institution, London, UK, 2004.

[32] Y. Anderberg and S. Thelandersson, "Stress and deformation characteristics of concrete at high temperatures. 2. experimental investigation and material behaviour model," Lund Institute of Technology Bulletin, vol. 54, 1976.

[33] Q. X. Le, J. L. Torero, and V. T. N. Dao, "Understanding the effects of stress on the coefficient of thermal expansion," International Journal of Engineering Science, vol. 141, pp. 83-94, 2019.

[34] F. J. Ulm, O. Coussy, and Z. P. Bažant, "The "chunnel" fire. i: chemoplastic softening in rapidly heated concrete," Journal of Engineering Mechanics, vol. 125, no. 3, 1999.

[35] B. M. Luccioni, M. I. Figueroa, and R. F. Danesi, "Thermomechanic model for concrete exposed to elevated temperatures," Engineering Structures, vol. 25, no. 6, pp. 729-742, 2003.

[36] H. G. Zhang, L. Li, C. Yuan, and Q. Y. Wang, "Deterioration of ambient-cured and heat-cured fly ash geopolymer concrete by high temperature exposure and prediction of its residual compressive strength," Construction \& Building Materials, vol. 262, 2020.

[37] F. Zhang, W. Hu, H. Q. Guo et al., "Nanoindentation tests on granite after heat treatment," Rock and Soil Mechanics, vol. 39, pp. 235-243, 2018. 
[38] X. Cai, C. G. Shi, X. H. Chen et al., "Identification of damage mechanisms during splitting test on SFP at different temperatures based on acoustic emission," Construction \& Building Materials, vol. 262, 2020.

[39] W. Li, X. Miao, and C. Yang, "Failure analysis for gas storage salt cavern by thermo-mechanical modelling considering rock salt creep," Journal of Energy Storage, vol. 32, 2020.

[40] T. T. Wang and T. K. Kwei, "Effect of induced thermal stresses on the coefficients of thermal expansion and densities of filled polymers," Journal of Polymer Science PART A-2: Polymer Physics, vol. 7, no. 5, pp. 889-896, 1969. 